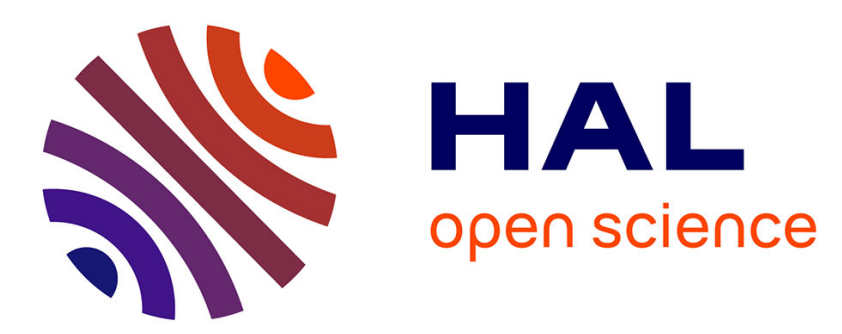

\title{
A planar on-chip micro-nib interface for NanoESI-MS microfluidic applications
}

S. Arscott, Séverine Le Gac, Christian Druon, Pierre Tabourier, Christian

Rolando

\section{- To cite this version:}

S. Arscott, Séverine Le Gac, Christian Druon, Pierre Tabourier, Christian Rolando. A planar onchip micro-nib interface for NanoESI-MS microfluidic applications. Journal of Micromechanics and Microengineering, 2004, 14 (2), pp.310-316. 10.1088/0960-1317/14/2/021 . hal-02347816

\section{HAL Id: hal-02347816 \\ https://hal.science/hal-02347816}

Submitted on 6 Jan 2021

HAL is a multi-disciplinary open access archive for the deposit and dissemination of scientific research documents, whether they are published or not. The documents may come from teaching and research institutions in France or abroad, or from public or private research centers.
L'archive ouverte pluridisciplinaire HAL, est destinée au dépôt et à la diffusion de documents scientifiques de niveau recherche, publiés ou non, émanant des établissements d'enseignement et de recherche français ou étrangers, des laboratoires publics ou privés. 


\title{
A planar on-chip micro-nib interface for NanoESI-MS microfluidic applications
}

\author{
Steve $\operatorname{Arscott}^{1,2}$, Séverine Le Gac ${ }^{2}$, Christian Druon ${ }^{1}$, \\ Pierre Tabourier $^{1}$ and Christian Rolando ${ }^{2}$ \\ ${ }^{1}$ Institut d'Electronique, de Microélectronique et de Nanotechnologie (IEMN), UMR \\ CNRS 8520, Cité Scientifique, Avenue Poincaré, 59652 Villeneuve d'Ascq cedex, France \\ ${ }^{2}$ Laboratoire de Chimie Organique et Macromoléculaire (LCOM), UMR CNRS 8009, \\ Université des Sciences et Technologies de Lille, Villeneuve d'Ascq, France \\ E-mail: Steve.Arscott@iemn.univ-lille1.fr
}

Received 13 May 2003, in final form 27 June 2003

Published 17 November 2003

Online at stacks.iop.org/JMM/14/310 (DOI: 10.1088/0960-1317/14/2/021)

\begin{abstract}
We present a novel nanoelectrospray emitter tip based on the principle of a nib rather than a nozzle for nano-electrospray ionization-mass spectrometry (ESI-MS) applications. The fabrication of the micro-nibs relies on micromachining techniques using the epoxy-based negative photoresist SU-8. A double exposure photolithographic process has been employed to form a nib in a membrane-like structure. The nibs contained a capillary slot measuring $20 \mu \mathrm{m}$ at the tip end. The nib sources were successfully tested on an ion trap mass spectrometer using standard peptide samples at low concentrations, down to $1 \mu \mathrm{M}$. High voltage (HV) supply was achieved using platinum wire inserted in a liquid reservoir. A Taylor cone was clearly seen protruding from the nib tip and was determined by the dimensions of the capillary slot.
\end{abstract}

\section{Introduction}

With the shrinking size of chemical and biological analysis tools [1-3], the evolution of microfluidic technology is mirroring that of the microelectronics industry in the quest for 'smaller, faster and cheaper' devices and systems. There is, hence, a current need for the development of new easy-to-fabricate analytical devices including reliable world-to-device interfaces. Microfluidic devices are being particularly developed for biological applications [4-7] as decreasing the device dimensions inevitably leads to decreasing the analysis time and thus increasing the throughput rate [3, 4, 7]. One way to detect species at the microsystem outlet is to use mass spectrometry (MS) techniques [8, 9]; electrospray ionization mass spectrometry (ESI-MS) is of particular interest when working with protein samples as ESI is a soft ionization method appropriate for large biomolecules, and MS is currently the most powerful technique for protein analysis and identification.

The production of gas phase ions from macromolecules dissolved in a liquid by electrospraying was first demonstrated by Dole et al [10] and then popularized as an ion source for mass spectrometry by Fenn et al [11]. Following this, nanoelectrospray ionization (nanoESI) sources were described using pulled silica $[12,13]$. These sources currently serve as the standard nanoESI-MS interface, small nozzles being formed from silica-based capillary tubes by heat treatment and pulling techniques. Such techniques give typical nozzle end dimensions of the order of $1-5 \mu \mathrm{m}$. However, this method of fabrication is ill controlled and gives poor reproducibility of the sources.

Unfortunately, this capillary-based coupling methodology is not compatible with the production of high-density electrospray devices, i.e. multi-system fabrication on a single chip. Hence, fabricating a nanoESI-MS interface using microtechnology techniques which exhibit similar or even better performances than usual fused-silica needle-like interfaces is a current technological challenge. The use of micromachining techniques will also increase the source reproducibility and robustness and thus enhance the analysis conditions.

Two main approaches for the fabrication of nanoelectrospray emitter tips have been reported, either micromachining an emitter tip with the shape of a nozzle or electrospraying from a microchannel outlet. 
The first approach is to micromachine an ionization source which resembles the usual electrospray emitter tips with a needle-like geometry; Lin and Pisano [14] described silicon nitride microneedles dedicated for drug delivery applications, and Lee et al [15] reported nozzles in silicon nitride and later needle structures in parylene [16]. Smith et al [17] described an array of nozzles fabricated in polycarbonate. Schultz et al [18] and Stemme et al [19, 20] developed similar monolithic silicon nozzles. The second approach gives better results in terms of the source dimensions; however, it should be noted that all the reported devices also worked under relatively highionization voltages and full integration of such sources into micro-systems has yet to be described.

The first attempt for electrospraying without needle-like usual emitter tips consisted of spraying directly from the outlet channel at the edge of the microsystem [21-23]; however, the liquid spread around the outlet and electrospray observation proved difficult. This was improved with a chemical treatment of the surface to render the channel output hydrophobic $[21,22]$, with a pneumatic assistance of the spray [23] or even by machining the edge of the system at the outlet so as to form a point-like structure [24-30]. In this way, Kameoka et al inserted a triangular parylene sheet between the two wafers so as to confine the liquid at the system outlet [24]. $\mathrm{Yu}$ and Shiea [25], Kim and Knapp [26-28] and Rossier et al $[29,30]$ have also explored the fabrication of such tapered structures to form an ionization source. However, in this approach the source dimensions are those of the microchannel and consequently, the high voltage (HV) value required to observe a spray was in the $2-3 \mathrm{kV}$ range. This is a relatively high value compared to the lower voltages, e.g., $1 \mathrm{kV}$, required for nanospray experiments.

Our work concerns the development of microfabricated ionization sources that function in nanoelectrospray conditions, that is to say under an applied voltage of the order of $1 \mathrm{kV}$ and with test liquid samples in the micromolar range. We present here a novel approach to this problem by the fabrication of a planar on-chip nib-like structure using the epoxy-based negative photoresist SU-8. The functioning of the micro-nib is much akin to that of a simple fountain pen in such that it contains a reservoir and an open capillary slot leading the test fluid to a nib point. An electrospray is then achieved by application of a high voltage as for any ESI source.

\section{Fabrication technology}

\subsection{NanoESI micro-nib design}

The micro-nibs have been fabricated on 3 inch silicon (100) wafers using the negative photoresist SU-8 (Microchem, MA). This photoresist is capable of producing very high aspect ratio features, and is thus starting to gain popularity with the microfluidics community [31, 32]. The micro-nib systems are composed of two parts: a main SU-8 feature fixed to the silicon wafer in order to support the micro-nib, and a second membrane-like feature containing a capillary slot which leads the protein sample to the end of the nib by capillary action. In addition, the main SU-8 incorporated a reservoir for the protein sample feeding the micro-nib during the MS test.

The fabrication of the micro-nibs is described in figure 1. A three inch silicon wafer was fully dehydrated
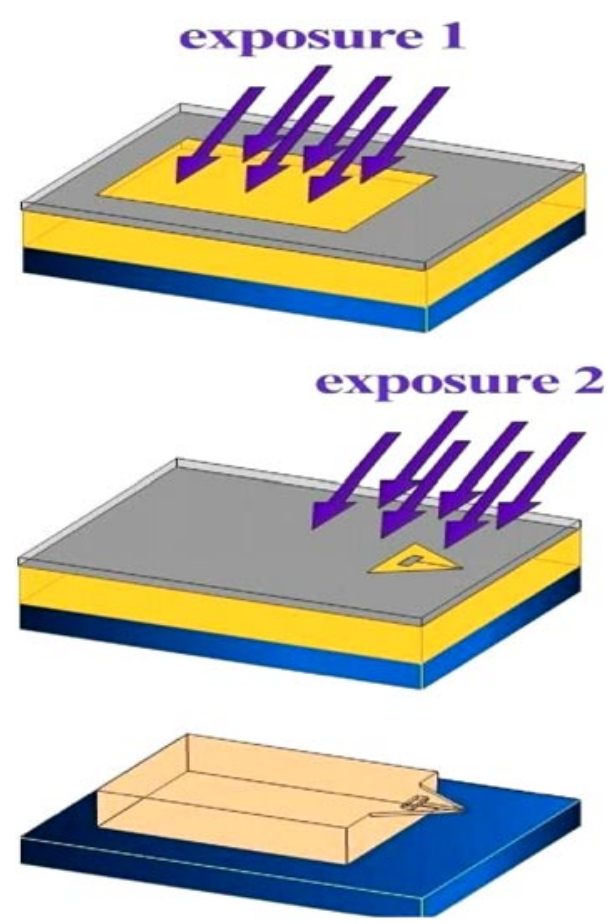

Figure 1. Fabrication steps for the fabrication of the micro-nibs. Exposure time 2 is less than exposure time 1 in order to form a membrane-like structure attached to the main SU-8 support feature.

at $170{ }^{\circ} \mathrm{C}$ for $30 \mathrm{~min}$ in order to ensure good adhesion of the SU-8 to the silicon surface. Following this, a $400 \mu \mathrm{m}$ thick layer of SU-8 2075 was deposited using standard spin-coating techniques in a class 100 clean-room. With such thick layers, special care is taken during the spread cycle in order to avoid bubble formation in the photoresist during the pre-bake. In addition, the hot-plate used for the pre- and post-bakes was made extremely leveled in order to ensure good planarity of the photoresist, this is essential in order to provide good wafer contact during the subsequent photolithographic steps. The initial nib support feature is formed in the SU-8 by using a single photolithographical masking step having an exposure time 1 . This time ensures complete polymerization of the SU-8 through the whole volume. Following this, a membranelike structure in a 'diving board' configuration is formed using techniques previously described by the authors [33]. This process involves the use of a second photolithographical masking stage and an exposure time 2. Exposure time 2 is less than exposure time 1 and has the effect of partial polymerization of the volume of the SU-8. The thickness of the resulting membrane-like structure has to be calibrated as a function of exposure time and the UV lamp intensity.

Figure 2 shows the thickness of the resulting SU-8 membrane-like structure as a function of exposure time at a lamp intensity of $7 \mathrm{~mW} \mathrm{~cm} \mathrm{~cm}^{-2}$. Table 1 shows the processing parameters used to form the micro-nibs using the SU-8 technology.

Alignment of the support and the nib-like structure is made possible either by using the existing exposed SU-8 support features or pre-metallized features deposited onto the silicon wafer prior to the SU-8 deposition. The nibs were aligned square to the wafer flats, i.e. along the (100) planes in order to 
Table 1. SU-8 processing parameters used for the fabrication of the planar micro-nibs.

\begin{tabular}{|c|c|c|c|c|c|c|c|c|c|c|c|}
\hline \multicolumn{3}{|c|}{ Spread cycle } & \multicolumn{3}{|c|}{ Spin cycle } & \multicolumn{2}{|c|}{$\begin{array}{l}\text { Pre-bake } \\
\text { (hot plate) }\end{array}$} & \multirow{2}{*}{$\begin{array}{l}\text { Exposure } \\
\text { time } 1 \\
\left(14 \mathrm{~mW} \mathrm{~cm}^{-2}\right) \\
\text { (s) }\end{array}$} & \multirow{2}{*}{$\begin{array}{l}\text { Exposure } \\
\text { time } 2 \\
\left(7 \mathrm{~mW} \mathrm{~cm}^{-2}\right) \\
(\mathrm{s})\end{array}$} & \multicolumn{2}{|c|}{$\begin{array}{l}\text { Post-bake } \\
\text { (hot plate) }\end{array}$} \\
\hline $\begin{array}{l}\text { Speed } \\
\text { (rpm) }\end{array}$ & $\begin{array}{l}\text { Acceleration } \\
\left(\mathrm{rpm} \mathrm{s}^{-1}\right)\end{array}$ & $\begin{array}{l}\text { Time } \\
\text { (s) }\end{array}$ & $\begin{array}{l}\text { Speed } \\
(\mathrm{rpm})\end{array}$ & $\begin{array}{l}\text { Acceleration } \\
\left(\mathrm{rpm} \mathrm{s}^{-1}\right)\end{array}$ & $\begin{array}{l}\text { Time } \\
\text { (s) }\end{array}$ & $\begin{array}{l}\text { Temperature } \\
\left({ }^{\circ} \mathrm{C}\right)\end{array}$ & $\begin{array}{l}\text { Time } \\
(\mathrm{min})\end{array}$ & & & $\begin{array}{l}\text { Temperature } \\
\left({ }^{\circ} \mathrm{C}\right)\end{array}$ & $\begin{array}{l}\text { Time } \\
(\mathrm{min})\end{array}$ \\
\hline 500 & 100 & 60 & 700 & 300 & 60 & 95 & 60 & 45 & 7.5 & 95 & 10 \\
\hline
\end{tabular}

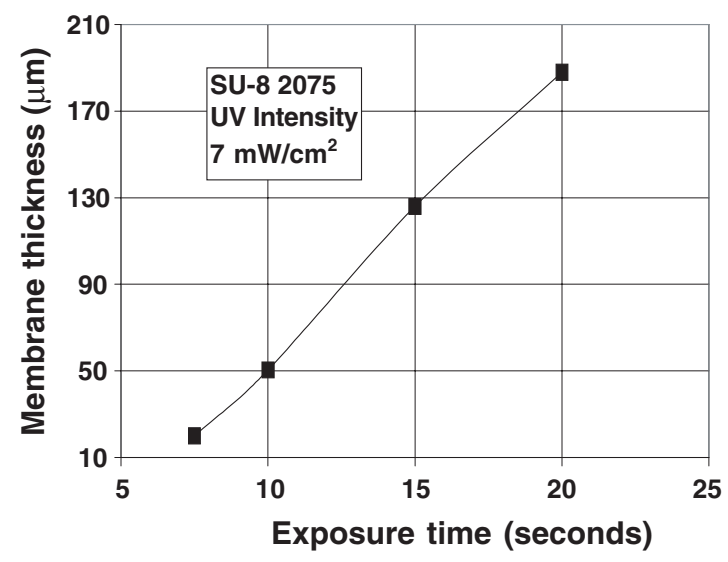

Figure 2. Thickness of SU-8 membrane-like structures as a function of exposure time (UV intensity of $7 \mathrm{~mW} \mathrm{~cm}^{-1}$ ).

ease the later wafer cleaving stage and thus leave the micronibs overhanging the wafer. In this way, we believe that many systems could be fabricated onto a single wafer either as worldto-chip interfaces or as stand-alone ESI-MS sources. The depth of the membrane-like structure was seen to be linearly proportional to the exposure time 2 and the exposure dose. A photoresist development step then releases the membrane-like micro-nib from the silicon wafer. It should be noted that the development time was not forced and some unexposed SU-8 was observed to be residual at the membrane-support feature interface.

Cleaving techniques are then employed to ensure that the micro-nibs hang over the edge of the $\mathrm{Si}$ wafer and ensure good interfacing to the mass spectrometer by avoiding possible arcing from the silicon substrate. Following the wafer dicing, the micro-nibs were seen to overhang the $\mathrm{Si}$ substrate by approximately $500 \mu \mathrm{m}$. Finally, a $100 \mathrm{~nm}$ thick layer of $\mathrm{SiO}_{2}$ was deposited onto the nibs using plasma-enhanced chemical vapour deposition (PECVD) techniques. Figure 3 shows an SEM image of a typical micro-nib that has been fabricated for this study (SEM taken prior to wafer cleaving). The smallest slot width on the mask was $20 \mu \mathrm{m}$ with a membrane depth at the tip of the micro-nib of around $30 \mu \mathrm{m}$. It should be noted that these were purposefully large dimensions compared to standard nanoESI-MS interface capillary tubes based on silica in order to facilitate the fabrication of prototype micro-nibs for these tests.

\subsection{Mass spectrometry tests}

The mass spectrometry tests were carried out on a LCQ Deca $\mathrm{XP}^{+}$ion trap mass spectrometer (Thermo Finnigan, WW). The nib sources were mounted on a $x y z$ moving part of the MS machine. The HV is usually supplied on the metallic zone of the moving part; a platinum wire was used to make the electrical contact between this metallic zone and the liquid dropped into the reservoir feature of the nib source. Once introduced in the ion trap inlet, the nib source position was adjusted in front of the mass spectrometer orifice using the $x y z$ micropositioning translational stage of the mass spectrometer. The micro-nib was then fed with the sample to be analysed that was dropped onto the reservoir feature of the nib upstream to the capillary slot. We used standard peptide solutions for testing the nib sources, Gramicidin S samples (Sigma, L'Isle d'Abeau, France). The solutions were prepared by diluting an aqueous stock solution at 100 pmol $\mu \mathrm{L}^{-1}$ using a $\mathrm{MeOH}$ : $\mathrm{H}_{2} \mathrm{O} 50: 50$ solution acidified with $0.1 \%$ of formic acid. Hence, we tested Gramicidin S samples at 50, 20, 10, 5 and $1 \mu \mathrm{M}$. The spray formation was observed using the camera mounted on the ion trap mass spectrometer giving a top view of the ESI-MS source. For all MS tests, the total ion current (TIC) signal was recorded over a period of $2 \mathrm{~min}$ and used to plot the resulting mass spectra in the $300-1500$ mass range using the Excalibur software. Comparison experiments were carried out with a Protana tip (Odensee, Denmark) in the standard conditions with the Gramicidin S sample at $1 \mu \mathrm{M}$ and under a $1 \mathrm{kV}$ ionization voltage.

\section{Results and discussion}

\subsection{Micro-nib design}

A first generation of nib sources have been designed and fabricated using the negative SU-8 photoresist; they were made hydrophilic by a $1000 \AA$ thick layer of $\mathrm{SiO}_{2}$ deposited on the resist. These sources consisted of the SU-8 structure on a silicon wafer with a reservoir feature and a capillary slot leading the liquid towards the nib point as seen on the schematic representation of a nib source in figure 3 .

The capillary slot is of $20 \mu \mathrm{m}$ width and $30 \mu \mathrm{m}$ depth, which is relatively large for a nanoelectrospray source but as mentioned above, with this first generation of nibs, we aimed simply at validating the nib source concept and proving that such a geometry was compatible with electrospray experiments. We have used the SU-8 photoresist as material for fabricating the nib structure as this resist allows the fabrication of rapid prototypes. The second step of the work will consist in improving the nib features and dimensions to enhance their functioning.

It should be noted that such a nib geometry should lend well itself for an on-chip integration with the capillary slot of the nib being the continuation of a microchannel; the fluid will thus be lead to the MS in a planar way. Such sources are also compatible with the production of high-density arrays of sources on a single wafer. For these first tests, we have fabricated a batch of isolated sources that were tested one by one but we plan to fabricate a series of integrated nib sources 


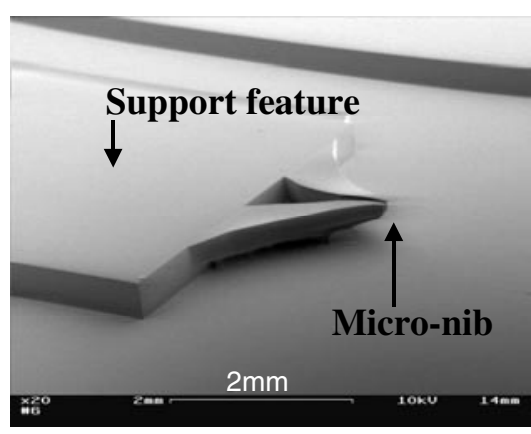

$(A)$

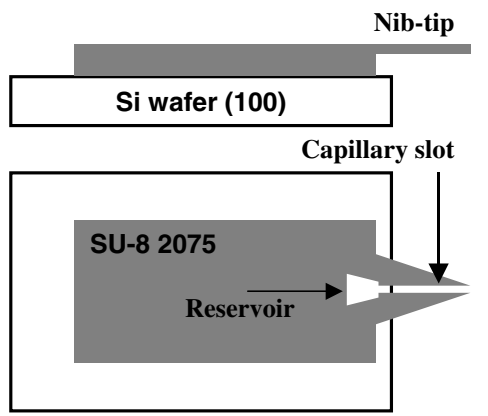

(B)

Figure 3. (A) SEM image of micro-nib fabricated in the SU-8 nib-like structure using the double exposure lithography technique described above; $(B)$ schematic plan and side views of the micro-nibs.

on a single silicon wafer. These nib sources can as well be used without any coupling to a microfluidic network, i.e. in stand-alone conditions. In this case, they appear to be easier to fill in than usual needle-like electrospray emitter tips, e.g., the Protana tips. Using the micro-nibs, the sample solution is simply deposited onto the reservoir feature. As a consequence, such sources with an open configuration would be easier to interface to a robot for high-throughput ESI-MS analysis.

The nib sources have first been tested without coupling to a mass spectrometer; liquid was dropped onto the reservoir and we checked by observing under a binocular microscope that the fluid was moving towards the nib point by capillary action.

\subsection{Mass spectrometry}

The nib sources were tested using mass spectrometry on an ion trap mass spectrometer. A platinum wire was inserted in the reservoir feature of the nib for HV supply, following this the micro-nib source was introduced into the MS inlet. A peptide sample was dropped onto the reservoir feature using a micropipette, and HV was then applied. We were able to observe the nib source operation; the fluid circulation within the reservoir and the slot and the formation of the spray using the camera mounted on the ion trap. The resulting Taylor cone dimensions are those of the nib slot at its extremity as seen on the photograph of a nib source facing the MS inlet (figure 4); here the applied HV was of $1.2 \mathrm{kV}$, this implied that the micro-nib source has to be moved very close to the trap inlet, and the Taylor cone was seen to be very elongated.

Due to the relatively large dimensions of the sources and due to the fact that we endeavoured to work with as low ionization voltages as possible, the nib sources were brought very close to the MS inlet, much nearer than the usual Protana tips. We worked with ionization voltages in the 1.2 to $2.5 \mathrm{kV}$, and we observed that the lower the HV value, the closer to the MS inlet the nib source has to be moved.

Tests were performed using gramicidin samples at a variety of concentrations, from 50 pmol $\mu \mathrm{L}^{-1}$ down to $1 \mathrm{pmol} \mu \mathrm{L}^{-1}$; this last concentration value was observed to be the limit of detection for these first prototypes. For every experiment we carried out with the nib sources, we observed an overall stability of the total ion current (TIC) signal, which reflects the stability of the spray, and an intensity comparable to

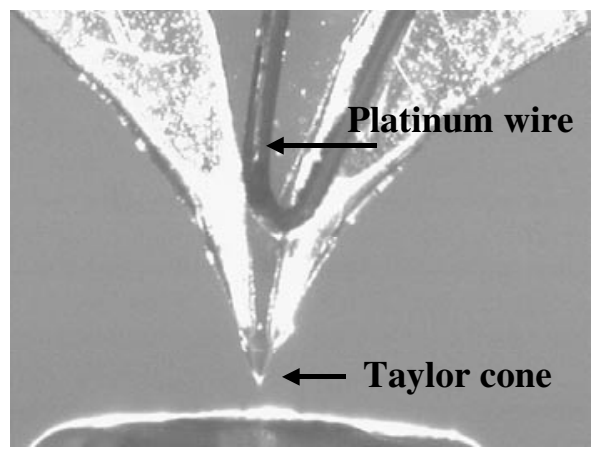

Figure 4. Photograph of nib during interfacing from the microsystem to MS with a $1.2 \mathrm{kV}$ voltage; the source has to be closer to the inlet due to the source dimensions. Note the spray formation at the nib extremity.

this obtained in standard conditions (the Protana tip as nanoESI source).

Figure 5 presents the TIC signal obtained over a period of $2 \mathrm{~min}$. with a nib source under a $\mathrm{HV}$ of $1.8 \mathrm{kV}$ and with a gramicidin sample at $10 \mu \mathrm{M}$. Mass spectra were plotted using the Excalibur software from Thermo Finnigan as a result of 2 min acquisition of the signal.

Figure 6 presents the mass spectra obtained under an ionization voltage of $1.8 \mathrm{kV}$ and with a solution of Gramicidin $\mathrm{S}$ at $5 \mu \mathrm{M}(A)$ and $1 \mu \mathrm{M}(B)$. As expected, the $(\mathrm{M}+\mathrm{H})^{+}$and the $(\mathrm{M}+2 \mathrm{H})^{2+}$ species, respectively, at $\mathrm{m} / \mathrm{z} 1141.7$ and $\mathrm{m} / \mathrm{z}$ 571.5 were detected with a very good signal-to-noise ratio. We compared the nib sources performances to those obtained in standard conditions on an ion trap mass spectrometer (Protana tip, $1 \mu \mathrm{M}$ peptide sample, $1 \mathrm{kV}$ ionization voltage). As already mentioned, the nib source position is different from this of the standard Protana tip as it was much closer to the inlet. Secondly, nib sources work with higher voltage values, as their optimal functioning was observed at $1.8 \mathrm{kV}$ with 5-10 $\mu \mathrm{M}$ samples. This accounts for the fact that the mass spectrum pattern is not the same for both types of sources; only the $(\mathrm{M}+2 \mathrm{H})^{2+}$ species at $m / z 571.5$ was detected with the Protana tip as both the singly and doubly charged species, respectively, $(\mathrm{M}+\mathrm{H})^{+}$at $m / z \quad 1141.7$ and $(\mathrm{M}+2 \mathrm{H})^{2+}$ at $\mathrm{m} / z .571 .5$ were detected with our nib-like sources with an intensity ratio depending on the $\mathrm{HV}$ value and the position of the nib in front of the MS inlet. However, the overall intensity was in the same range; the resolution was seen to 


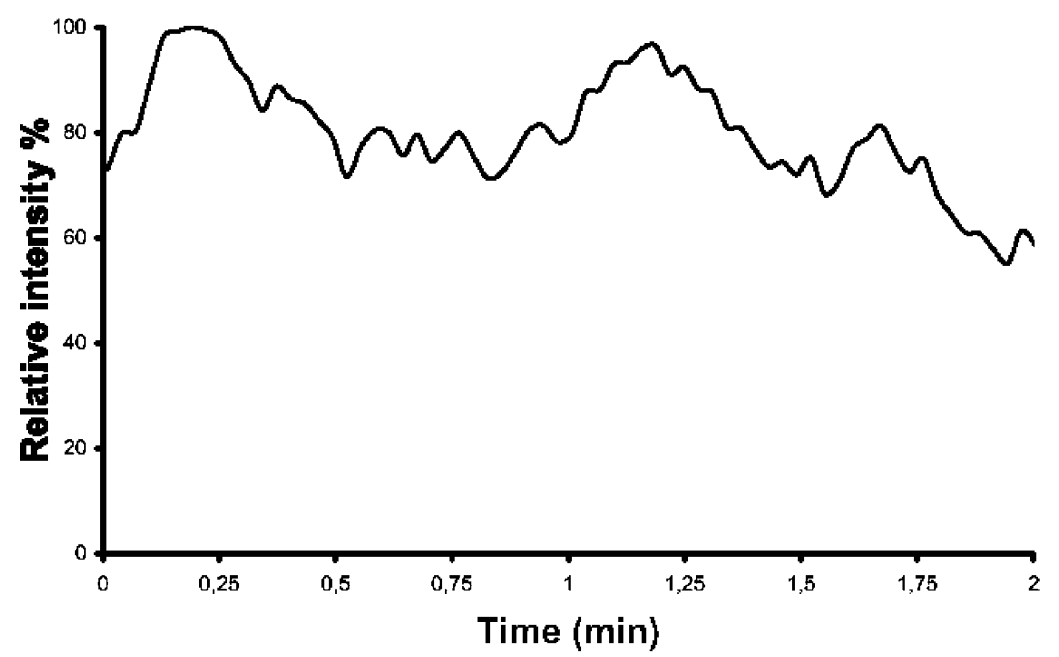

Figure 5. Total ion current (TIC) signal observed for a nib source facing the ion trap mass spectrometer; recording of the signal over a period of 2 min with a sample of Gramicidin $\mathrm{S}$ at $10 \mu \mathrm{M}$ and under a $\mathrm{HV}$ of $1.8 \mathrm{kV}$.

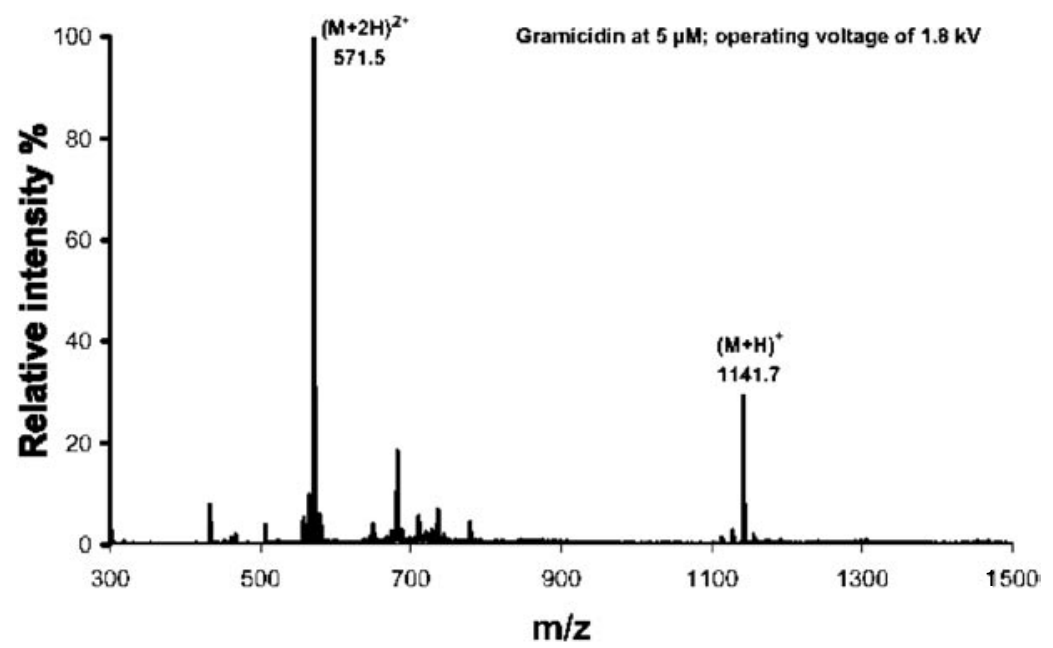

$(A)$

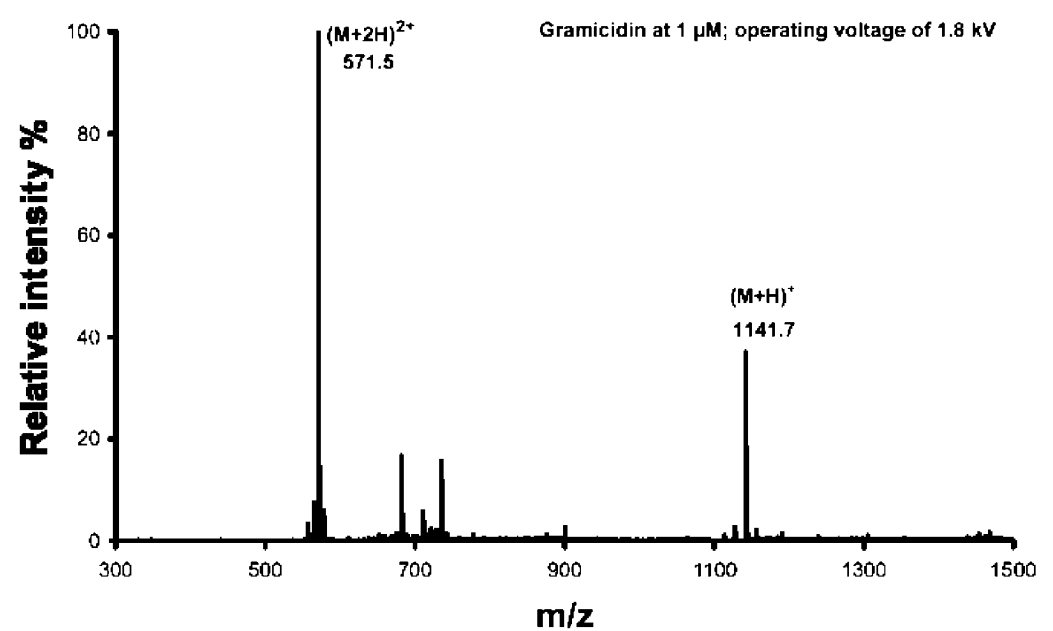

$(B)$

Figure 6. Mass spectra obtained with a solution of Gramicidin $\mathrm{S}$ and resulting from a 2 min acquisition of the signal. (A) sample at $5 \mu \mathrm{M}$ and $\mathrm{HV}$ of $1.8 \mathrm{kV}$ and $(B)$ sample at $1 \mu \mathrm{M}$ and $\mathrm{HV}$ of $1.8 \mathrm{kV}$. We detect in both cases the $(\mathrm{M}+2 \mathrm{H})^{2+}$ and the $(\mathrm{M}+\mathrm{H})^{+}$ionized species of the Gramicidin S, respectively, at $m / z$ of 571.5 and $m / z$ of 1141.7 
be similar in a zoomscan experiment, and the fragmentation spectrum presented a similar pattern with both types of sources. Nevertheless, even if the performances are much the same, we are aware that improving the design and dimensions of the nib sources is required so as to enhance the analysis conditions in nanospray-mass spectrometry.

\section{Conclusion}

We have proposed, fabricated and tested a novel nanoESIMS world-to-chip interface. This interface is composed of a micro-nib and is based on the idea of a simple fountain pen in such that an open capillary slot feeds a test liquid from a reservoir to a nib tip. The capillary slot had dimensions of $20 \times 30 \mu \mathrm{m}$ at the tip. The micro-nibs were fabricated using the negative photoresist SU-8 on Si wafers. A stable electrospray has been achieved along with the observation of a Taylor cone protruding from the tip of the capillary slot. We have also demonstrated the capability of theses sources for the analysis of peptide samples under pretty good conditions, samples in the $\mu \mathrm{M}$ range and $\mathrm{HV}$ value around $1.5-1.8 \mathrm{kV}$. We believe this idea to be compatible with both channelbased and digital microfluidic circuits. We intend to optimize the micromachining and further shrink these dimensions in order to reduce the working voltages, to enhance the analysis conditions and to work in conditions closer to nanospray ones. We are currently working on fabricating similar micro-nibs in SU-8 using novel fabrication methods in order to achieve smaller dimensions and thus generate nanosprays at lower working voltages.

\section{Acknowledgments}

This work was financially supported by the Ministère de 1'Industrie: Bio-Ingénierie 2001-Réseau Genhomme and by the Ministère de la Recherche et des Nouvelles Technologies: Réseau Micro et Nanotechnologies with the integrated proteomic project. The mass spectrometry facilities used in this study was funded by the European Union (FEDER), the Région Nord-Pas de Calais (France), the CNRS and the Université des Sciences et Technologies de Lille. The authors thank Christophe Boyaval (IEMN) for the SEM images.

\section{References}

[1] Reyes D R, Iossifidis D, Auroux P-A and Manz A 2002 Micro-total analysis systems. 1: Introduction, theory and technology Anal. Chem. 74 2623-36

[2] Reyes D R, Iossifidis D, Auroux P-A and Manz A 2002 Micro-total analysis systems. 2: Analytical standard operations and applications Anal. Chem. 74 2637-52

[3] Krishnan M, Namasivayam V, Lin R, Pal R and Burns M A 2001 Microfabricated separation and reaction systems Curr. Opin. Biotec. 12 92-8

[4] Figeys D and Pinto D 2000 Lab-on-a-chip: a revolution in biological and medical sciences Anal. Chem. 330A-5A

[5] Guetens G, van Cauwenberghe K, de Boeck G, Mes R, Tjaden U-R, van der Greef J, Highley M, van Oostrerom A-T and de Bruijn E-A 2000 Nanotechnology in bio/clinical analysis J. Chromatogr. A 739 139-50

[6] Mouradian S 2001 Lab-on-a-chip: applications in proteomics Curr. Opin. Chem. Biol. 6 51-6
[7] Khandurina $\mathbf{J}$ and Guttman A 2002 Bioanalysis in microfluidic devices J. Chromatogr. A 943 159-83

[8] Nelson R W, Nedelkov D and Tubbs K A 2000 Biosensor chip mass spectrometry : a chip-based proteomics approach Electrophoresis 21 1155-63

[9] Oleschuk R D and Harrison D J 1999 Analytical microdevices for mass spectrometry Trans. Anal. Chem. 19 379-88

[10] Dole M, March LL, Hines R L, Mobley R C, Ferguson L P and Alice M B 1968 Molecular beams of macroions J. Chem. Phys 49 2240-9

[11] Fenn J B, Mann M, Meng C K, Wong S F and Whitehouse C M 1989 Electrospray ionization for the mass spectrometry of large biomolecules Science 246 64-71

[12] Valaskovic G A, Kelleher N L, Little D P, Aaserud D J and McLafferty F W 1995 Attomole-sensitivity electrospray source for large-molecule mass spectrometry Anal. Chem. 67 3802-5

[13] Wilm M S and Mann M 1996 Analytical properties of the nanoelectrospray ion source Anal. Chem. 68 1-8

[14] Lin L and Pisano P 1999 Silicon processed microneedles IEEE J. Micromech. Syst. 8 78-84

[15] Desai A, Tai Y-C, Davis M T and Lee T D 1997 A MEMS electrospray nozzle for mass spectrometry Int. Conf. on Solid-State Sensors and Actuators, Transducers ' 97

[16] Licklider L, Wang X-Q, Desai A, Tai Y-C and Lee T D 2000 A micromachined chip-based electrospray source for mass spectrometry Anal. Chem 72 367-75

[17] Tang K, Lin Y, Matson D W, Kim T and Smith R D 2001 Generation of multiple electrosprays using microfabricated emitter arrays for improved mass spectrometric sensitivity Anal. Chem. 73 1658-63

[18] Schultz G A, Corso T N, Prosser S J and Zang S 2000 A fully integrated monolithic microchip electrospray device for mass spectrometry Anal. Chem 72 4058-63

[19] Griss P, Melin J, Sjodahl J, Roeraade J and Stemme G 2002 Development of micromachined hollow tips for protein analysis based on nanoelectrospray ionization mass spectrometry J. Micromech. Microeng. 12 682-7

[20] Sjoedahl J, Melin J, Griss P, Emmer A, Stemme G and Roeraade J 2003 Characterization of micromachined hollow tips for two-dimensional nanoelectrospray mass spectrometry Rapid Commun. Mass Spectrom. 17 337-41

[21] Ramsey R S and Ramsey J M 1998 Generating electrospray from microchip devices using an electroosmotic pumping Anal. Chem 70 3721-7

[22] Xue Q, Foret F, Dunayevskiy Y M, Zavracky P M, McGruer N E and Karger B L 1997 Multichannel microchip electrospray mass spectrometry Anal. Chem. 69 426-30

[23] Zhang B, Liu H, Karger B L and Foret F 1999 Microfabricated devices for capillary electrophoresis-electrospray mass spectrometry Anal. Chem 71 3258-64

[24] Kameoka J, Orth R, Ilic B, Czaplewski D, Wachs T and Craighead H G 2002 An electrospray ionization source for integration with microfluidics Anal. Chem. 74 5897-901

[25] Yuan C and Shiea J 2001 Sequential electrospray analysis using sharp-tip channels fabricated on a plastic chip Anal. Chem. 73 1080-3

[26] Kim J S and Knapp D R 2001 Microfabrication of polydimethylsiloxane electrospray ionization emitters J. Chromatogr. A 924 137-45

[27] Kim J-S and Knapp D R 2001 Microfabricated PDMS multichannel emitter for electrospray ionization mass spectrometry J. Am. Soc. Mass Spectrom. 12 463-9

[28] Kim J S and Knapp D R 2001 Miniaturized multichannel electrospray ionization emitters on polydimethylsiloxane microfluidic devices Electrophoresis 22 3993-9

[29] Gobry V, Oostrum J, Martinelli M, Rohner T C, Reymond F, Rossier J S and Girault H H 2002 Microfabricated polymer injector for direct mass spectrometry coupling Proteomics $\mathbf{2}$ 405-12

[30] Rossier J S, Youhnovski N, Lion N, Damoc E, Becker S, Reymond F, Girault H H and Przybylski M 2003 Thin-chip 
microspray system for high-performance Fourier-transform ion-cyclotron resonance mass spectrometry of biopolymers Angew. Chem. Int. Ed. Engl. 42 53-8

[31] Lin C-H, Lee G-B, Chang B-W and Chang G-L 2002 A new fabrication process for ultra-thick microfluidic microstructures utilizing SU-8 photo resist J. Micromech. Microeng. 12 590-7
[32] Zhang J, Tan K L, Hong G D, Yang L J and Gong H Q 2001 Polymerization optimization of SU-8 photoresist and its applications in microfluidic systems and MEMS $J$. Micromech. Microeng. 11 20-6

[33] Arscott S, Duvillaret L, Mounaix P, Garet F, Coutaz J-L and Lippens D 1999 Terahertz time-domain spectroscopy of films fabricated from SU-8 Electron. Lett. 35 243-4 